\title{
THE BRITISH STANDARD FOR SPECTACLE LENSES*
}

\author{
BY \\ NIGEL CRIDLAND
}

Portsmouth

THE prescriber who orders spectacles intends his patient to have an optically efficient appliance, and the introduction of a British Standard for Spectacle Lenses is a major advance towards realizing this intention. Dispensing is the translation of an idea into a fact, but the prescriber is concerned only with the effect of his idea and he should be free to assume that the idea (his prescription) has been accurately translated into the fact (the spectacles). The intermediate steps ought not to concern him, and it is the purpose of this British Standard to remove some of the uncertainties in the translation.

A British Standard, in any field, is normally a definition of the best in current practice. It is, first, a practicable standard; it is, second, a high standard; it is, third, a desirable standard. It is usually prepared by consolidating the experience of all parties interested in the field into a draft specification, criticism of which is then widely invited. The criticisms and the draft are reconciled in the British Standard, which thereafter controls the quality of work done to its specification. It is, as it were, a hall-mark.

In this new Standard, the British Standards Institution has sought the help of a wide range of interested parties, and it is a tribute to its methods that the draft specification drew little criticism when comment was invited from both home and abroad. Now it stands on its own feet, an acceptable challenge to manufacturer and dispenser and a guarantee to prescriber and patient. It is still open to criticism, or to amendment if necessary. Revision normally takes place every 5 years, but may be made earlier if it appears to be required.

The Standard defines the accuracy normally to be expected for the power of a lens, its centration, the axis-setting of a cylinder, and the power and axis of a prism. It considers lenses taken as a pair, and touches on other related matters such as edging and marking. All these are technical problems of dispensing, but the Standard also contains matters which prescribers should note, because the aphorism about the strength of a chain is valid here. The back vertex power of a lens is used throughout, and the prescriber who wishes to take advantage of the British Standard should accustom himself to thinking of lenses in terms of this measure. As a corollary, the lens-cornea distance becomes more important both in refraction and in prescribing and, tedious though it is, this measurement should

* Received for publication February 15, 1956. 
be routinely made in both acts. There is need for an effective and rapid tool for making it, preferably incorporated in the trial-frame.

"Tolerances" are the limits of permissible departure from a stated measure, and are commonly set at one-half of the smallest customary step or interval $\underset{\vec{s}}{\vec{\rho}}$ in the stated measure. Thus, where the quarter-dioptre is the smallest step $\frac{\overrightarrow{0}}{0}$ in general use in prescribing, one-eighth dioptre would usually be the toler- $\frac{}{0}$ ance applied. But manufacture becomes rapidly more expensive as pre- $\overrightarrow{\bar{p}}$ cision increases, and the tolerances chosen are therefore a compromise $\stackrel{\varnothing}{\mathscr{\perp}}$ which states only what is normally permissible. Greater precision is obtain- ® able, but the cost may be prohibitive. It follows that prescribers should $\overrightarrow{0}$ have in mind the size of the zone that the tolerances will give, and should $\vec{\omega}$ not seek to prescribe within narrower limits without remembering that extra cost is probably implied.

There remain, of necessity, areas of indefiniteness in the field. Some of $\dot{0}$ these the B.S.I. hopes later to remove by definition, while in some definition $\vec{\circ}$

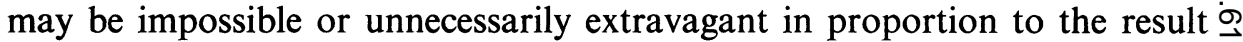
to be achieved. But in one area the Institute is already working, and a $\vec{\circ}$ companion document on spectacle frames is under consideration. Together, $\stackrel{3}{\rightarrow}$ they should remove almost entirely the prescriber's concern about dispensing, $\bigcirc$ and in the meanwhile this British Standard should be welcome to all who are interested in the outcome of the prescription. 